\title{
LAST PLANNER® SYSTEM ON THE MINNEVIKA BRIDGE PROJECT
}

\author{
Sajad Daliri' ${ }^{1}$, Brendan K. Young ${ }^{2}$, and Ola Lædre ${ }^{3}$
}

\begin{abstract}
Construction companies around the world have adopted the Last Planner® System (LPS) to reduce variability, increase workflow and improve reliability on their projects. This study explains the implementation of LPS in an infrastructure (railway bridge construction) project. Strengths and weaknesses of the implementation were examined and possible measures to overcome the experienced challenges were discussed. Finally, attitude changes towards the LPS during the project were measured.

Data was collected through case-specific observations, semi-structured interviews with open-ended questions, and two surveys. The findings revealed that the project benefitted from implementing LPS, but benefits could have been reinforced if critical team members had participated continuously in the necessary meetings, followed the system without resistance and maintained their commitments. Additionally, LPS on the Minnevika bridge project was the novel start and detected challenges are often experienced by every organization at the beginning of implementation of a new system. Indeed, the Minnevika bridge project can be considered as a point of departure and being persistent will help the parties to benefit even more in the next project.
\end{abstract}

\section{KEYWORDS}

Last Planner® System, challenges, infrastructure, attitude.

\section{INTRODUCTION}

Since the construction industry plays a vital role in economy, society, environment (Ansah et al. 2016), reducing waste and increasing productivity is important. The existing failures reported in the traditional project management help define the requirements for a new approach. This approach has been adapted to the construction industry, namely lean construction (Pellicer et al. 2015). The Last Planner ${ }^{\circledR}$ System is one of the most popular lean tools which has been used in construction to improve management and control, reduce urgent procurement requests, improve the performance(Alarcón et al. 2011), and for continuous monitoring of planning efficiency (O. AlSehaimi et al. 2014).

Several of the largest construction companies in Norway have shown their interest in LPS or what they call "Collaborative Planning (Veidekke and Kruse Smith), Trimmed Construction (Skanska) and Collaborative Project Execution (Nymo)" in their operations

MSc Candidate, Norwegian University of Science and Technology (NTNU), Trondheim, Norway/PNC Norge AS, Oslo, Norway, +4796859654, sajadd@stud.ntnu.no, orcid.org/0000-0002-3355-8807

2 Managing Site Manager, PNC Norge AS, Oslo Norway, +4747713728, brendan.young@ @nc-norge.no, orcid.org/0000-0003-2532-8670

3 Associate Professor, Norwegian University of Science and Technology (NTNU), Trondheim, Norway, +4773594739, ola.ladre@ ntnu.no, orcid.org/0000-0003-4604-8299 
(Kalsaas and Grindheim 2014). PNC Norge AS, the company under-study, is one of these organizations that has implemented LPS on their Minnevika bridge project to improve planning and control, reduce uncertainty, take advantages of efficient collaboration among contractors and subcontractors, and measure the weekly project progress. When it comes to LPS implementation, the specific cultural barriers such as attitude to work could show up (Johansen and Porter 2003). However, by considering cultural analysis tools and measurements, it is possible to find out the factors of success or failure of certain practices in cultural conditions (Ravi et al. 2018). A significant number of case studies of implementation of LPS in projects exists, but few have investigated the participants' attitude changes towards LPS implementation on an infrastructure project who have adopted the LPS for the first time. Therefore, the following research questions were formulated:

- How is the Last Planner® System practiced on the Minnevika bridge project?

- What are the strengths and weaknesses of the LPS process on the Minnevika bridge project?

- How have the involved parties' attitudes towards challenges changed during the implementation of LPS?

After the introduction section, the research methods are explained. Then, the literature review concentrates on LPS stages and challenges. The case study findings are presented and discussed before the research questions are answered in the conclusion section.

\section{LITERATURE REVIEW}

\section{LAST Planner@ System COMPONENTS}

Last Planner@ System is a holistic and cascade system that helps construction companies improve planning reliability, production performance, and workflow on construction sites (Hamzeh,2011). The integrated components of this system include milestone planning, phase planning, look-ahead planning, weekly work planning, and learning (Ballard and Tommelein, 2016).

\section{Milestone planning}

The front-end planning process that, besides defining the project milestones and the required length of time for performing each activity, provides an overview of entire tasks that should be executed throughout the project (Daniel et al. 2017).

\section{Phase planning}

By utilizing the milestone planning and incorporating input from different project parties (direct involvement of the contractors, sub-contractors, clients, and other stakeholders), reliable construction planning will be developed at this stage to cover each project phase as a reverse phase scheduling back from important milestones (Hamzeh et al. 2012).

\section{Look-ahead planning}

It is medium term planning approximately six weeks in advance and screens for constraints in eight flows, which includes resources, information, equipment, material, prerequisites, safe workplace, external conditions (Koskela 2000) and common understanding (Pasquire and Court 2013) before passing the activities into production on site in order to increase construction flow. (Daniel et al. 2017). 


\section{Weekly work planning}

The weekly work planning takes place every week with the involvement of last planners in order to review the commitments planned in the previous week. It involves making a schedule for the week ahead and defining the detailed assignments that should be performed during that week (Pellicer et al. 2015).

\section{Learning}

Measuring the reliability of the plan that is directly related to the productivity (Pellicer et al. 2015) is possible by applying measurement indicators such as; Percentage Plan Complete (PPC) for evaluating the proportion of commitments that are delivered on time and the reason for non-completion (RNC) in order to learn from the mistakes and avoid them in future (Ballard and Tommelein 2016).

\section{Last Planner@ System Challenges}

Many construction companies have made attempts to take advantage of the LPS. However, it should be noted that besides the numerous benefits of this tool, many organizations face significant implementation obstacles (Ballard et al. 2007; Viana et al. 2010). As Hamzeh (2011) stated "researchers in the field of change management and lean have reported attempts of many organizations to implement lean practices. However, most companies either failed or only partially achieved lean production in its true form". According to Hamzeh (2011), both general and local factors can impact implementation of LPS. General factors relate to the execution of a new method and include: human resources, organizational inertia, resistance to change, technological barriers. Local factors relate to project circumstances and include; relatively new experience in lean methods, traditional project management methods, the newness of LPS to team members, lack of leadership, and team chemistry. Similarly, Porwal et al. (2010) categorized the challenges into two parts; 1 . Challenges faced during the implementation phase such as lack of training, partial or late implementation of LPS, lack of support and contractual structure. 2. User challenges, for instance, lack of commitment and attitude toward the new system, lack of collaboration, extra resources or time consuming, and lack of understanding of new system. It should be noted that the most LPS challenges tend to be related to the softer aspects of implementation including organizational process and people (Dave et al. 2015). Kassab et al. (2020) followed the initial implementation of LPS on the Minnevika Bridge Project and Table 6 lists the challenges they identified.

\section{RESEARCH METHODS}

To answer the research questions, data was collected through case specific observations, semi-structured interviews with open-ended questions, and two surveys. An initial literature study was carried out to identify the core components of LPS and the challenges related to implementing LPS. Findings from literature were used when establishing an interview guide and formulating the survey questions.

The Minnevika bridge project was selected as a case study since it is one of the first infrastructure projects in Norway to implement LPS. It consists of 2 abutments and 18 piers standing on $268 \varnothing 1016 / 20 \mathrm{~mm}$ steel tube friction piles. When opening for traffic in August 2023, this $836 \mathrm{~m}$ long concrete bridge will be the longest in Norway. It is part of the Norwegian railway operator BaneNor's Eidsvoll Nord-Langset 4.5 kilometer doubletrack rail development that in addition to the Minnevika bridge includes a short tunnel and three short bridges. A joint venture was established between Hæhre AS and PNC 
Norge AS to deliver the total project. Within the joint venture, PNC Norge acts as the main contractor for the Minnevika bridge.

The first author was employed as a trainee on the Minnevika project and supported the LPS facilitator both in the weekly work meetings and with preparing the LPS documentation. The first author was an participant-observer who followed the guidelines of Saunders et al. (2009) while conducting observations. Notes were taken from the observations of 9 weekly work meetings. The second author was an ordinary participant in these meetings, but not an observer. These two authors' participation led to an in-depth knowledge about the project but may also have led to a biased analysis despite attempts to avoid it.

Three semi-structured interviews were collected during the LPS implementation with two site managers and one project planner. The interview questions were structured after the three research questions.

Two more or less similar surveys were distributed in February 2019 and November 2020 with the same participants. The first survey was answered by 8 participants and the second by 9. Findings from the first survey are reported by Kassab et al. (2020). Collecting data with the two surveys conducted with an interval of one year allowed for a longitudinal study to be presented here.

\section{FINDINGS}

\section{LPS ImPlementation On the MinneViKa BRIDGe Project}

The implemented LPS on the Minnevika bridge project consists of a Milestone plan, Look-ahead plans and the Weekly work plans. The contractor's site managers and supervisors established the Milestone plan at the beginning of the project. The milestones are tied to the major activities in the project. The Milestone plan represents the top of the plan hierarchy and decides the room for manoeuvre in the Look-ahead plan and the more detailed Weekly work plan.

With the Milestone plan as the starting point, the Look-ahead plans were established. The contractor used the milestone plan to map the bridge construction activities from the beginning to the end by pull planning principles. The mapping included an identification of all activities that had to be completed to reach each milestone. The necessary order, the duration and the critical path for these activities were identified. Then, a pull planning of the activities from their last date of completion was carried out. The respective first possible start date for the activities on the critical path gave the available time. Hopefully the available time is sufficient. The team used this backwards - or reverse - planning of the workflow to establish the Look-ahead plan from the milestone plan. Look-ahead plans on the Minnevika bridge project were for six weeks ahead and required representatives of the main contractor and the subcontractors to plan reliably and identify constraints.

The construction managers, site engineers, production team, HSE representatives, partners and subcontractors participated in the Weekly Work Plan (WWP) meetings. On the Minnevika bridge project, the term Production Evaluation and Planning (PEP) is used for the activities that correspond to the LAP and WWP described in literature. The agenda in the PEP meeting had standard headings: evaluation of the previous week, checking the Reason for Non-Completion (RNC) of trades (part of handover management between the trades, and the Minnevika project use the term Variance Analysis), Order and safety (analyse the safety issues on the construction site), Risk matrix (risks/constraints with 
corresponding probability and consequences), Action Plan (with responsibles and deadlines, to mitigate risks and promote opportunities), LAP, WWP, and Logistics.

The contractor measured the following Key Performance Indicators (KPI): Percent Plan Complete (PPC) overall, PPC per trade, Milestone Completion, Variance Analysis (or RNC), Top Three Variances, and Problem Solving. The indicators were tracked and used in order to increase productivity and learning from mistakes.

\section{The LPS ON MinNeViKa COMPARED TO LPS IN LITERATURE}

The Last Planner® System on the Minnevika bridge project consists of five components described as essential in literature, namely milestone planning, backwards planning, lookahead planning, weekly work planning and measurements for learning. Even though the contractor only applied LPS in the execution phase and not in the design phase, the core components of LPS were in place.

Table 1: LPS components on the Minnevika bridge project

\begin{tabular}{cccccc}
\hline & $\begin{array}{c}\text { Milestone } \\
\text { plan }\end{array}$ & $\begin{array}{c}\text { Phase } \\
\text { planning }\end{array}$ & $\begin{array}{c}\text { Look-ahead } \\
\text { planning }\end{array}$ & $\begin{array}{c}\text { Weekly work } \\
\text { planning }\end{array}$ & $\begin{array}{c}\text { Measurement \& } \\
\text { Learning }\end{array}$ \\
\hline In place & $\checkmark$ & $\checkmark$ & $\checkmark$ & $\checkmark$ & $\checkmark$ \\
\hline
\end{tabular}

\section{STRENGTHS AND WEAKNESSES OF LPS - EXPERIENCES FROM MINNEVIKA}

To understand the productivity and efficiency of LPS on the Minnevika bridge project, it is vital to determine the benefits and drawbacks of the system from the participants' perspective who were involved in implementation of LPS. After analyzing the notes from the participant observations and the transcripts from the interviews with the project team, it seemed that the strengths overweighted the weaknesses. A majority of the project participants' experienced LPS for the first time, and they thought that if LPS were implemented on future projects with the same participants some of the weaknesses would fade away more or less by themselves. During the interviews, the strengths and weaknesses of the LPS execution as well as possible solutions for the shortcomings were examined. The results related to the milestone plan, lookahead plan, weekly work plan and KPIs are described in table 2-5 below, respectively. Each table is followed by a discussion.

Of those weaknesses identified - both for the Milestone, Look-ahead and Weekly work plan - many of them seemed to be the result of irregular attendance of participants in the meetings. An observation was that it often was the same participants that did attend and and the same that did not. Put in other words; some participants were not loyal to the plans, and their unloyalty spoilt potential benefits for all. The success of LPS demands that all - or at least most - of the participants act loyal.

A measure to overcome the challenges related to the Milestone plan in table 2 - that emerged during the observations and interviews - was to review the milestones periodically. A periodic review would remind the participants about the main milestones in the project and prevent that the short-term look-ahead planning occupied all attention. 
Table 2: Strengths and weaknesses of the Milestone plan

\section{Strengths}

- Higher level management uses it to track project progress

- Suitable as report to the client

- Gives a target plan on the entire project

- Can be used when prioritising which activities can be delayed and which can be speeded up

\section{Weaknesses}

- Does not include all activities on site

- Can be forgotten since it is not in everyday use

Table 3: Strengths and weaknesses of the Look-ahead planning

\section{Strengths}

- The involved parties cooperate on a reliable detailed plan for decisions, activities and resources with the critical path benefitting the project as a whole for.

- $\quad$ Planning on whiteboard with colourful sticky notes helps visualize the process and improve understanding

- Helps participants to reflect and plan clearly

\section{Weaknesses}

It sometimes creates a short-term focus

- $\quad$ Since Look-ahead planning is time consuming it can lead participants to rush into the actual planning

Suggested measures to mitigate the challenges in table 3 related to Look-ahead planning at the Minnevika bridge project included to increase consciousness about how the sixweek look-ahead plan fits the Milestone plan. The milestone plan should to a larger extent have been used as a reference for the continuous look-ahead planning, as the milestone plan was not always consulted when the look-ahead plan was updated to match progress on site. The result was that the updated look-ahead plan was not fully aligned with the milestone plan. However, since the updated look-ahead plans were not substantially changed, the missing alignment was not expected to cause future problems. Another suggested measure was to assign people to activities, and thereby increase consistency in who was responsible for the planning.

Table 4: Strengths and weaknesses of the Production evaluation and production planning (PEP)/Weekly work plan (WWP)

\section{Strengths \\ Weaknesses}

- A weekly meeting that helps the team coordinate both internally• with partners and with the subcontractors

Some supervisors did not attend the meetings

- One meeting substitutes separate meetings with individual subcontractors

- Allow discussions on all issues with involved parties

- Make the production team commit to the plan

- Participation in planning motivates the foremen

- Participants with different perspectives provide input to

- $\quad$ Time consuming (around two hours)

- Parts of the meetings were irrelevant to some participants

- Rotational working schedules distort continuous participation appropriate solutions

It is not easy to ask experienced managers to adopt new ways of management, and that caused the weaknesses of the PEP meetings listed in table 4 . The best way to convince these managers to spend the necessary time is by convincing them of the benefits of the system. During the observations, some benefits appeared. As one of site managers explained: "The PEP meeting helps us to have one coordination meeting instead of having meetings one by one with all our partners and subcontractors separately. Now we get everyone in the same room and when a problem comes up, we have more people to contribute and look at it from different angles to make better solutions". Another measure 
that appeared during the observations and the interviews is to put more efforts into establishing the PEP meeting schedule. The meeting schedule must be aligned with the relevant participants' presence on site, and not at least with which time of the day that works best for the participant's rotation, their tasks on site, and their meeting schedule.

Table 5: Strengths and weaknesses of the KPI

\section{Strengths}

- Supports communication of lessons learned

- Prevents repetition of mistakes

- Comparison of progress compared to plan

- Reveals reliability of the superior plan

\section{Weaknesses}

- Hard to attract the participants' attention to the KPI

- Participants usually do not analyse and track changes after PEP meetings

The KPIs were measured, but as identified in Table 5, the participants in the PEP meetings were not eagerly embracing the entailing opportunities. A suggested measure to overcome the weaknesses was to demonstrate how the measurements of Percent Plan Complete (PPC), Milestone Completion, Variance Analysis (Reasons for Non-Completion), and Top Three Variances could be used to improve the workflow for the participants.

\section{Measuring the Involved Parties’'Attitudes During the Project}

To measure changes in the participants' attitudes towards the LPS, two surveys were distributed to project participants with around one year interval. Both surveys contains questions based on challenges identified by Kassab et al. (2020), who reported the findings from the first survey. When distributing the surveys with one year interval, it was possible to observe how attitudes changed after the participants acquainted themselves with the LPS. The changes in average score (from $1=$ very low to $5=$ very high on a Likert Scale) from February 2019 to November 2020 are given in Table 6.

Table 6: To what extent do you think each of the following challenges is considered as a critical challenge on the Minnevika Bridge project during execution phase (average scores from 1-5)? (developed from Kassab et al. (2020))

\begin{tabular}{lcc}
\hline \multicolumn{1}{c}{ Challenges } & Feb & Nov \\
& $\mathbf{2 0 1 9}$ & $\mathbf{2 0 2 0}$ \\
\hline 1. Maintaining people's commitment to be part of the process and take the system seriously & 3.50 & 3.22 \\
2. Lack of transparency in the interfaces between project team members & 2.25 & 2.77 \\
3. Resistance to the system & 2.25 & 3.22 \\
4. The language barriers & 1.63 & 2.00 \\
5. Non-participation of critical team members & 2.85 & 3.22 \\
6. The decisions and input are primarily provided by top-level management, such as site & 3.00 & 2.88 \\
managers & 3.00 & 2.22 \\
7. Fear of responsibility (mainly from lower-level management) & 1.63 & 2.77 \\
8. Doubt (about overall performance and benefits behind the LPS) & Feb & Nov \\
\hline \multicolumn{1}{c}{ Challenges } & $\mathbf{2 0 1 9}$ & $\mathbf{2 0 2 0}$ \\
\hline 9. Misunderstanding of the basic concepts of the LPS & 2.00 & 2.22 \\
10. The time commitment required to participate in the weekly meeting & 1.75 & 2.77 \\
11. Lack of engagement & 1.63 & 2.00 \\
12. Disruption & 1.63 & 2.33 \\
\hline
\end{tabular}




\section{Attitudes have Changed}

When comparing the scores from February 2019 with the scores from November 2020, it appears that the scores have changed after a year. Three of the challenges originally identified by Kassab et al. (2020) are considered to have become less critical after a year. Maintaining participants' commitment to be part of the process and to take the system seriously was the main challenge during the first stage of LPS implementation and is still one of the three top challenges. It has become slightly less significant with time. Similarly, the decisions and input are primarily provided by top-level management, such as site managers and Fear of responsibility (mainly from lowerlevel management) have followed the same trend. One reason why these challenges are considered less critical after a year may be that the project team has gained more experience with LPS after one year, and that the participants see that LPS is practiced according to theory.

The comparison of the scores from the first survey with the scores from the second survey reveals - somewhat surprisingly - that nine out of twelve challenges are considered to have become more critical after a year. The nine challenges are Lack of transparency in the interfaces between project team members, Resistance to the system, The language barriers, Non-participation of critical members, Doubt (about overall performance and benefits behind the LPS), Misunderstanding of basic concepts of the LPS, The time commitment required to participate in the weekly meeting, The lack of engagement and Disruption. These challenges are maybe considered more critical after a year, as the participants realise that the promised benefits of LPS are not manifesting as quickly as hoped for. In addition, the project team might have experienced that LPS's charm of novelty has faded during the year, and that implementation of LPS requires persistence. They need to put in resources to make LPS work, and the resources may outweigh the benefits for projects that implement LPS for the first time. The next project may not need that much resources to realise the benefits.

The suggested explanations for why three challenges have become less critical (more experience and LPS practiced according to theory) could have been used to explain a decrease in the nine remaining challenges as well. However, the nine other challenges increased. The other way around, the suggested explanations for why nine challenges have increased (promised benefits not manifesting, charm of novelty has faded out, implementation requires persistence and resources outweigh benefits) could have been used to explain an increase in the three. The exact reasons for why three challenges decreased, and nine challenges increased were not in-depth investigated.

\section{CONCLUSIONS AND FUTURE WORK}

This paper set out to answer three research questions, namely, 1) how is the Last Planner® System practiced on the Minnevika bridge project, 2) what are the strengths and weaknesses of the LPS process on the Minnevika bridge project from participants' perspectives and 3) how have the involved parties' attitudes towards challenges changed during the implementation of LPS. The answers to these three research questions are based on the findings from studying the implementation of LPS on one railway bridge construction project and are considered valid for other infrastructure projects that plan to implement LPS for the first time.

The answer to the first research question is that the contractor on the Minnevika bridge project has implemented five core components described by literature as essential, namely 
milestone planning, phase planning, look-ahead planning, weekly work planning and measurements for learning.

The participants recognise typical strengths of LPS and have experienced improved planning and control during the execution phase. Some project team members did not invest as much resources in following up LPS as others, but if they had done so the typical strengths could have been reinforced. Despite that some participants did not put sufficient efforts into LPS, the implementation resulted in improved coordination between the contractor and the partners, and between the contractor and the subcontractors. The participants believed that if they implemented LPS more faithfully on their next project, several of the experienced weaknesses would fade and strengths could probably even be boosted because of the training they acquired on the Minnevika project.

The answer to the third research question about how have the involved parties' attitudes towards challenges changed during the implementation of LPS, is that three observed challenges are considered to have become less critical while nine challenges are considered to have become more critical. Since the project team has gained experience with LPS and see that it works, the three challenges are less critical. Since the project team also sees that making LPS work demands continuous effort, the other nine challenges are considered more critical after a year. Successful implementation of LPS not only relies on the application of the full version of the tool, but also on changes in mindset and project team participation. LPS does not represent a quick fix.

The Minnevika bridge will open for traffic in August 2023. To collect more data and quality assure the conclusions in this study, it is recommended to carry out more interviews and distribute a third survey to measure the attitudes towards LPS right before the project is finished. The third survey should look for the exact reasons why some challenges decrease and some increase by time.

\section{ACKNOWLEDGMENTS}

We would like to express our great appreciation to PNC Norge AS, the Minnevika Bridge Project team, and Norwegian University of Science and technology for their cooperation and support.

\section{REFERENCES}

Alarcón, L. F., Diethelm, S., Rojo, O., and Calderón, R. (2011). “Assessing the impacts of implementing lean construction." Revista Ingeniería de Construcción, 23(1) 2633.

Ansah, R. H., Sorooshian, S., and Mustafa, S. B. (2016). "Lean Construction: An Effective Approach For Project Management." ARPN Journal of Engineering and Applied Sciences., 11(3) 1607-1612.

Ballard, G., Kim, Y.-W., Liu, M., and Yang, J. (2007). "Roadmap for Lean Implementation at the Project Level." The Construction Industry Institute., p.426

Ballard, G., and Tommelein, I. (2016). "Current Process Benchmark for the Last Planner System.” Lean Construction Journal., 89 57-89.

Daniel, E. I., Pasquire, C., Dickens, G., and Ballard, H. G. (2017). "The relationship between the last planner ${ }^{\circledR}$ system and collaborative planning practice in UK construction." Engineering, Construction and Architectural Management., 24(3) 407-425. 
Dave, B., Hämäläinen, J.-P., and Koskela, L. (2015). "Exploring the Recurrent Problems in the Last Planner Implementation on Construction Projects." Institute for Lean Construction Excellence.

Hamzeh, F. (2011). "The Lean Journey: Implementing The Last Planner ® System in Construction." Proceedings of the 19th Annual Conference of the International Group for Lean Construction, IGLC 13-15.

Hamzeh, F., Ballard, G., and Tommelein, I. (2012). "Rethinking Lookahead Planning to Optimize Construction Workflow.” Lean Construction Journal (LCJ)., 2012 15-34.

Johansen, E., and Porter, G. (2003). "An experience of introducing last planner into a UK construction project."

Kalsaas, B. T., and Grindheim, I. (2014). "Integrated Planning Vs. Last Planner System." 22nd Annual Conference of the International Group for Lean Construction, IGLC 639-650.

Kassab, O., Young, B., and Lædre, O. (2020). “Implementation of Last Planner® System in an Infrastructure Project". 28th Annual Conference of the International Group for Lean Construction, IGLC., 517-528.

Koskela, L. (2000). "An exploration towards a production theory and its application to construction”. VTT Technical Research Centre of Finland, Espoo.

AlSehaimi, A.O., Fazenda, P.T., and Koskela, L. (2014). "Improving construction management practice with the Last Planner System: a case study." Engineering, Construction and Architectural Management., 21(1) 51-64.

Pasquire, C., and Court, P. (2013). "An Exploration Of Knowledge And Understanding The 8th Flow." 22nd Annual Conference of the International Group for Lean Construction, IGLC 43-52.

Pellicer, E., Cerveró, F., Lozano, A., and Ponz-Tienda, J. L. (2015). "The Last Planner System of Construction Planning And Control As A Teaching And Learning Tool." INTED2015 Proceedings, 9th International Technology, Education and Development Conference., 4877-4884.

Porwal, V., Fernandez-Solis, J., Lavy, S., and Rybkowski, Z. (2010). "Last planner system implementation challenges." Proceedings of the 18 Annual Conference International Group for Lean Construction, IGLC 548-556.

Ravi, R., Lædre, O., Fosse, R., Vaidyanathan, K., and Svalestuen, F. (2018). "The Last Planner System: Comparing Indian and Norwegian Approaches." 26th Annual Conference of the International Group for Lean Construction., 381-391.

Saunders, M., Lewis, P., and Thornhill, A. (2009). "Research Methods for Business Students. Pearson Education."

Viana, D. D., Mota, B., Formoso, C. T., Echeveste, M., Peixoto, M., and Rodrigues, C. L. (2010). "A Survey on The Last Planner System: Impacts And Difficulties For Implementation Brazilian Companies." 18 th Annual Conference of the International Group for Lean Construction., 497-507. 